\title{
EVASÃO ESCOLAR: AS CAUSAS E AS CONSEQUÊNCIAS DE UMA NEGLIGÊNCIA SOCIAL
}

\author{
Nilma Maria de Oliveira Leal ${ }^{1}$
}

\begin{abstract}
RESUMO
O presente estudo tem por objetivo apresentar uma discussão acerca da evasão escolar, apontando suas causas, elucidando as possíveis consequências individuais e sociais, e abrindo pontos discursivos acerca de quais medidas podem ser tomadas de acordo com as demandas aplicadas nessa temática. Partindo de uma análise bibliográfica, foram selecionados teóricos que discutem a relação da evasão escolar com a decadência estrutural do país, buscando encontrar pontos de conexão entre o posicionamento social e as desistências ocorridas no contexto educacional. Trata-se de uma visão ampla sobre a atual posição de jovens e adultos não escolarizados no contexto educacional de ensinoaprendizagem.
\end{abstract}

Palavras-Chave: Evasão. Escolar. Desistências.

\section{EVASION SCHOOL:}

\section{THE CAUSES AND CONSEQUENCES OF A SOCIAL NEGLIGENCE}

\section{ABSTRACT}

The present study aims to present a discussion about school dropout, pointing out its causes, elucidating the possible individual and social consequences, and opening discursive points about which measures can be taken according to the demands applied in this theme. Based on a bibliographical analysis, we selected theorists who discuss the relationship between school dropout and the country's structural decay, seeking to find points of connection between social positioning and dropouts occurring in the educational context. It is a broad view of the current position of young people and adults not enrolled in the educational context of teaching and learning.

Keywords: Evasion. School. Withdrawals.

\footnotetext{
${ }_{1}^{1}$ Nilma Maria de Oliveira Leal - Programa de Pós graduação em Educação - UNIGrendal Teixeira de Freitas - Bahia / CEP: 45992-255 < nilmamarialeal@hotmail.com >
} 


\section{INTRODUÇÃO}

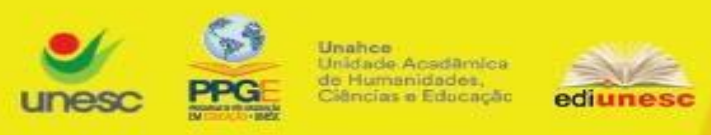

Muito se tem discutido sobre a inclusão no ambiente escolar, mas a forma como essa inclusão vem sendo aplicada não tem contemplado grande parte do corpo estudantil. A presente pesquisa é de cunho bibliográfico e busca tratar acerca da evasão escolar no Brasil, considerando esse fato, em parte, como um fracasso no processo de inclusão escolar. Para realizar essa análise foram selecionados uma gama de teóricos que discutem a temática segundo a situação educacional do país.

O problema da evasão escolar preocupa não só a escola e seus representantes, como toda a comunidade externa. Ao identificar alunos com pouca vontade de estudar, ou com importantes atrasos na sua aprendizagem, nota-se que esses indivíduos tendem a desistir da sua formação antes de concluir o ensino básico. Nesse sentido, é preciso considerar que a evasão escolar é uma situação problemática, que se produz por uma série de fatores aos quais envolvem toda a comunidade, os profissionais da educação e os representantes legais.

É de interesse esclarecer que será usado o termo "evasão escolar" segundo o estabelecido pelo INEP (Instituto Nacional de Estudos e Pesquisas Educacionais Anísio Teixeira), para maiores esclarecimentos, o termo é significado no corpo da pesquisa. Aqui, entende-se que para modificar a estrutura vigente da educação é necessário discutir a sua atual situação, entender as suas lacunas, aceitar as próprias culpas e eximir-se daquelas que não pertencem a si.

Para isso, essa pesquisa não pretende apontar culpados, uma vez que compreende-se o quão complexo e recheado de questões é o âmbito educacional, e, em especial a evasão escolar. Propõe-se então, identificar as responsabilidades governamentais, escolares e individuais, para que dessa forma possamos compreender as causas e juntos pensarmos em uma proposta de combate-las.

A partir daí, considera-se necessária a aproximação daqueles estudiosos e pesquisadores que se ocuparam em desvendar o problema da evasão escolar. Utilizar-se-á da Constituição federal para compreender a proposta educacional ideal na recuperação dos jovens evadidos, uma vez que o que se propõe nas leis voltadas para esses aspectos não se cumpre, tornando assim, a educação de grande parte da 

população inviável. Com o auxílio das ideias de Gentili (2008) será discutido o posicionamento social em relação a evasão e como a variação financeira e a estrutura social influenciam no ensino e nas eventuais desistências aqui dissecadas. Para trabalhar o fracasso escolar frente à inclusão do aluno, o que desencadeia em mais um dos fatores de evasão, far-se-á uso de Ferreira (2013). E dentro dessa mesma temática, abordando as reprovações, será trazido à luz os pensamentos e estudos de Patto (1997). Mendes (2013), de mesmo modo essencial, preencherá nosso aporte teórico ao nos indicar uma discussão sobre o papel da motivação no processo de ensino-aprendizagem.

Por fim, essa pesquisa não busca em si mesma um fim, mas sim, um ponto de reflexão acerca da atual condição da educação no país, fazendo uso de teóricos e estudiosos da área para ilustrar um posicionamento frente a essa grande fragilidade na educação que é a evasão dos alunos em todos os níveis educacionais, mas, principalmente na educação básica.

\section{DESENVOLVIMENTO}

A Constituição Federal de 1988 determina a universalização do ensino fundamental e a erradicação do analfabetismo no território brasileiro, metas ainda hoje inalcançadas. Sobre o processo de disseminação do ensino e as consequências de uma tentativa desordenada de aplicar o ensino nas instituições públicas, Araújo (2014) irá nos dizer que:

Com a democratização passou, também, a se buscar a universalização do ensino. Busca essa que influenciou categoricamente para o processo de sucateamento e privatização do sistema escolar público, isto é, para a fuga dos grupos mais afortunados para o sistema de ensino privado. (ARAÚJO, 2014, p. 128)

O autor chama atenção para a fragmentação e enfraquecimento da educação pública em vista da educação privada a qual cresce mais a cada dia. Dessa forma, a população que já enfrenta múltiplos obstáculos na sua caminhada educacional ainda 
sofre com a desvalorização da única opção educacional cabível em sua realidade financeira.

Visto isso, percebemos que apesar da educação ter ganho muitas batalhas durante a guerra contra o analfabetismo, de lá pra cá se estagnou em um conformismo inacreditável. As escolas de ensino gratuito foram desprezadas financeiramente e a população mais carente colheu os frutos desse descaso, enquanto as classes média alta e alta recorriam e recorrem à educação privada para uma melhor preparação educacional. A existência dos analfabetos funcionais e a própria evasão escolar em quaisquer grau de ensino é uma prova irrefutável dessa realidade, até porque, a evasão ocorre justamente nas classes menos favorecidas da população. Gentili (2008) esclarece a esse respeito que:

Os sistemas educacionais nacionais não pararam de crescer e ampliar seu alcance, passando a incluir parcelas da população historicamente excluídas do acesso às instituições escolares [...] estes mesmos sistemas intensificaram sua tendência à segmentação, reproduzindo as persistentes formas de segregação que marcaram seu desenvolvimento histórico. Criaram assim, novas dinâmicas de exclusão endógenas, cada vez mais complexas e difusas. (GENTILI, p. 29, 2008)

O autor nos traz uma visão mais ampla e difundida do que seria a caminhada da educação de brasileiros e brasileiras. Ao passo que a educação superou algumas barreiras histórico-sociais, como a não existência de instituições de ensino para as classes menos abastadas, ao mesmo tempo foi-se criando novas e mais complexas barreiras, como a precarização das instituições públicas de ensino e a insuficiência profissional no preparo dos profissionais que assumiriam os postos de professores dessa classe, fragilizando o ensino público e aumentando o número de desistentes e analfabetos funcionais.

Sabe-se que para além da escola em si, a educação engloba toda a condição de vida do cidadão, uma vez que um aluno que esteja em uma situação de vulnerabilidade, seja por não ter segurança de moradia, não possuir uma alimentação adequada ou quaisquer outros fatores externos ao ambiente de ensino. Sobre essas singularidades que assolam o campo educacional o autor explica que:

Apesar da promessa de que o acesso à escola garantiria a conquista de melhores condições de vida, milhões de latino-americanos e latinoamericanas viram suas oportunidades educativas se ampliarem, enquanto suas condições de vida se deterioravam drasticamente. (GENTILI, p.32, 2008) 
Aqui o autor aborda um gatilho para o abandono escolar em virtude da procura exasperada por meios de sobrevivência, pois, mesmo com maiores oportunidades de escolarização, uma população que não possui condições básicas de sobrevivência, não poderá ocupar grandes espaços no meio acadêmico. A esse respeito ele ainda complementa:

Sociedades cada vez mais injustas não podem ter se não sistemas educacionais também injustos e discriminatórios. Injustiças e discriminações que nascem de um sistema fortemente heterogêneo e desigual. (GENTILI, p.36, 2008)

Deste modo o autor já nos indica um elemento responsável pela degradação geral da educação: a própria sociedade. Uma vez que a sociedade não está adaptada ao indivíduo, muito menos as escolas pautadas nesse ideal de sociedade o estarão. O problema da escolarização - ou não escolarização - brasileira encontra suas raízes muito mais profundas. A formação política e estrutural da nação inviabiliza o desenvolvimento educacional da parcela de sua população mais carente.

Mas afinal, se o indivíduo frequenta a escola, se alfabetiza...o que classifica de fato a evasão escolar? No projeto A evasão na Unipampa - diagnosticando processos, acompanhando trajetórias e itinerários de formação, da Universidade Federal do Pampa (2010), José, Broilo, Andreoli apud Inep definem o abandono escolar e suas causas da seguinte maneira:

Evasão escolar: i) $O$ mesmo que deserção escolar. 1. Fenômeno que expressa o número de educandos de um grau de ensino ou de uma série escolar, que abandonam definitiva ou temporariamente a escola (México, 1969); ii) Pessoa que se afastou do Sistema de Ensino, por haver abandonado o estabelecimento, do qual era aluno frequente, sem solicitar transferência. Educandos que por razões financeiras de inadaptação, entre outras, não completaram um determinado período de formação. A Evasão escolar ocorre por motivos geralmente atribuídos às dificuldades financeiras, ao ingresso prematuro no mercado de trabalho, à troca de domicílio, à doença, à falta de interesse do aluno ou de seus responsáveis, às dificuldades de acesso à escola, aos problemas domésticos, à separação dos pais ou à reprovação do aluno (I GLOSED); iii) Sérgio G. Duarte caracteriza a evasão como uma expulsão escolar, porque a saída do aluno da escola não é um ato voluntário, mas uma imposição sofrida pelo estudante, em razão de condições adversas e hostis do meio (cf. DBE, 1986); iv) A grande maioria dos estudantes evadidos deixa a escola no segundo semestre por se considerar incapaz de passar de ano (Fontes em educação, $O$ que é...? COMPED, 2001). Abandono escolar: Abandono de curso ao término de um ano letivo. Desistência de atividades escolares por parte do aluno. A desistência supõe afastamento do estabelecimento de ensino, não- 

atendimento às exigências de aproveitamento e de assiduidade e não solicitação de transferência para outro estabelecimento (cf. I GLOSED).

A extensa definição de "evasão escolar" esbarra bem sutilmente na falta de vontade do aluno em continuar os seus estudos, indicando desse modo, que as condições oferecidas a esse estudante é que de fato definem o seu trajeto educacional. Vale ressaltar que um número muito pequeno de estudantes de fato não possuem interesse em continuar os seus estudos, e ainda esses, costumam estar desinteressados por encontrarem no mercado de trabalho precoce uma solução imediata para suas demandas. Ferreira (2013) endossa essa visão disforme da educação quando afirma que "o fracasso escolar e a consequente evasão denotam o próprio fracasso das relações sociais". A evasão não é consequência de apenas um fator social ou econômico, ela está vinculada a vários fatores que juntos trazem um grande prejuízo acadêmico para o país. Trata-se de uma realidade que infecciona toda a sociedade, atingindo a todos, como bem pontua Patto (1997) ao redefinir a evasão escolar:

\begin{abstract}
A reprovação e a evasão escolar são: um fracasso produzido no dia-a-dia da vida na escola e na produção deste fracasso está envolvido aspectos estruturais e funcionais do sistema educacional, concepções de ensino e de trabalho e preconceitos e estereótipos sobre a sua clientela mais pobre. Estes preconceitos, no entanto, longe de serem umas características apenas dos educadores que se encontram nas escolas, estão disseminados na literatura educacional há muitas décadas, enquanto discurso ideológico, ao se pretender neutro e objetivo, participa de forma decisiva na produção das dificuldades de escolarização das crianças das classes populares. (PATTO, p. 59, 1997)
\end{abstract}

Tomando os pensamentos do autor, pode-se notar que a evasão escolar está tão emaranhada de fatores que disseca-los nos tomaria inúmeras páginas, e, de fato não é a proposta desse estudo, ao qual visa proporcionar uma reflexão acerca da situação decorrente. As dificuldades enfrentadas pelos estudantes estão além da metodologia de ensino ou do acesso a uma instituição escolar, as razões das desistências se encontram nas práticas pedagógicas aplicadas de forma displicente, nos livros didáticos que não levam em conta as peculiaridades do público ao qual serve, das condições financeiras, psicológicas, dos ambientes familiares conturbados, e de mais uma centena de fatores aos quais unidos impossibilita a continuação do aluno no seio escolar. Discutir, portanto, uma solução imediata para um problema que 
finca suas raízes nas estruturas que formam as políticas públicas do país se torna irrelevante. O problema é estrutural, e a solução, de mesmo modo deve ser estrutural.

Informações do senado federal indicam que no ano de 2018 mais de 2,8 milhões de crianças e adolescentes em idade escolar estão fora da sala de aula. Os números são alarmantes. E vale ressaltar que tais números desconsideram os analfabetos funcionais, discutido previamente neste trabalho.

Algumas ações para modificar esse quadro de ensino já foram tomadas e aplicadas. Ainda que o sucesso dessas práticas tenha sido insuficiente para contemplar uma mudança geral do quadro educacional. Um exemplo dessas ações foi a implementação do EJA (Educação de Jovens e Adultos), uma iniciativa que contempla cidadãos que não tiveram oportunidade de participar do processo de escolarização na idade ideal, ou que de alguma forma foram levados a ser estatística de evasão escolar, mas que agora desejam passar por essa etapa acadêmica.

Apesar de iniciativas como a citada acima possuírem grande relevância no desenvolvimento educacional, ainda não são o ideal. A educação tardia impossibilita uma aprendizagem completa, além de obrigar o educando a dividir o seu tempo entre os afazeres domésticos, trabalho formal ou informal para obtenção de renda e a escola, quando o ideal na alfabetização - visando o público infantil - é dedicação exclusiva do aluno à aprendizagem. A parcela da sociedade a qual compõe as classes média e alta disponibilizam a suas crianças tempo hábil para a dedicação exclusiva ao ensino, sem preocupações com alimentação ou moradia, fato que coloca essas pessoas em uma posição privilegiada em relação a parcela mais carente da população.

Por fim, não se pode deixar de abordar, ao discutir a evasão escolar, o fator "motivação". Afinal, a desmotivação se torna um grave empecilho, para além de todas as singularidades já citadas, quando refere-se ao ambiente escolar, como bem pontua Bzuneck (2009) apud Mendes (2013) ao dizer que:

a queda na motivação leva a um declínio no investimento pessoal para realizar as tarefas de aprendizagem com qualidade, o que impossibilita a formação de indivíduos mais competentes para exercerem a cidadania e se realizarem como pessoas. 
O autor nos traz à luz um fato a muito discutido nas salas de aula de ensino superior das licenciaturas brasileiras: afinal, o que eu, professor, posso fazer para evitar a exclusão dos meus alunos? A resposta, como pode-se ver ao decorrer deste artigo não é simples, nem objetiva e muito menos definitiva. Ouso dizer que dentre todos os fatores aos quais se desencadeiam a exclusão de alunos por quaisquer razão a qual desemboca na evasão escolar, a única que apetece ao professor seja esta última, a motivação. Se cabe ao estado providenciar o que já garante pela constituição, o direito à moradia, alimento e educação dignas, à família, um ambiente propício ao desenvolvimento psicológico e emocional, ao professor irá caber o encaminhamento desse aluno quanto à motivação. É simples perceber a importância desse fator quando pensamos que muitas vezes a única motivação presente na vida desse aluno pode ser a ofertada por seu professor. Entende-se que o profissional da educação não possui condições propícias para lidar com todas questões dos alunos, porém, um profissional que não trabalhe a motivação de seus alunos, pode não só não ajudar, como também auxiliar na possível desistência desse indivíduo na própria caminhada acadêmica.

Não se trata, portanto, de uma solução objetiva, imediata e certeira, mas sim, de um processo no qual muitas entidades deverão estar envolvidas, se trata de um problema estrutural com uma extensa lista de causas e com uma triste demanda de consequências, afinal, uma perca na educação é uma perca para toda a sociedade. Visto isso, a proposta aqui apresentada é de reflexão, afinal, os responsáveis pela melhora de condições possíveis para o avanço da educação no Brasil são todos os indivíduos que fazem parte da sociedade, e somente através desses indivíduos poderá haver cobranças sérias ao governo vigente, responsável pelas condições externas desfavoráveis ao ensino.

\section{CONSIDERAÇÕES FINAIS}

Essa discussão não possui um fim em si mesma, e tampouco era presunção desse artigo que possuísse. A partir das teorias apresentadas, das reflexões e 
discussões propostas, o que pode-se concluir de fato é que a educação precisa urgentemente ser repensada por todos aqueles envolvidos com ela de alguma forma.

Não há um culpado, uma entidade que possa de fato resolver instantaneamente o problema de inúmeros brasileiros sem educação básica, sendo levados por "enes" fatores a desistir de sua formação, mas isso não quer dizer que nada deva ser feito afinal. A discussão apresentada visa a reflexão da situação atual da educação, levando em conta a responsabilidade da família, do governo e dos profissionais envolvidos diretamente com o ensino e com a escola.

Enquanto profissionais da educação, nos cabe trabalhar diariamente com a motivação do alunado, fazendo com que este, tenha consciência da importância do estudo para a sua formação enquanto indivíduo. Vale acrescentar ainda que nenhuma forma motivacional irá surtir efeito se não considerarmos o ambiente e as condições peculiares pelas quais nossos alunos passam. Sabemos que a educação é um trabalho conjunto e que enquanto professores não podemos suprir as demandas familiares e sociais, porém se cumprirmos as nossas demandas, um grande passo já estará sendo dado.

Quanto às políticas sociais e educacionais cabe a nós cobrar ao governo enquanto cidadão e profissionais da educação ações que ao menos amenizem a precarização geral da educação. É preciso que nossos alunos não tenham que escolher entre sua formação e seu alimento diário, entre concluir o ensino básico e continuar tendo uma moradia e uma vida minimamente descente. Para começar a resolver os problemas de evasão, é necessário compreender as suas raízes sociais e combater todos os fatores. Não existem medidas imediatas para problemas estruturais.

\section{REFERÊNCIAS}

ARAÚJO, Jurandir de Almeida. Educação e desigualdade: A conjuntura atual do ensino público no Brasil. Rev. Direitos Humanos e Democracia: Editora Unijuí, 2014 p. $125-157$ 
Criar Educação, Criciúma, v. 8, no2, ago/dez 2019.- PPGE - UNESC - ISSN 2317-2452

BRASIL. Constituição Federal de 1988. Promulgada em 5 de outubro de 1988. Disponível em: <http://www.planalto.gov.br/ccivil_03/constituicao/constituição.htm>. Acesso em: 04 Set. 2018.

FERREIRA, F. A. Fracasso e evasão escolar. 2013. Disponível em:<http://educador.brasilescola.com/orientacao-escolar/fracasso-evasaoescolar.htm>. Acesso em: 03 Set 2018.

GENTILI, Pablo. Desencanto e Utopia: A educação no labirinto dos novos tempos. Petrópolis, RJ: Vozes, 2008

JOSÉ, Adriano Rodrigues; BROILO, Cecília Luiza; ANDREOLI, Giovani Souza. A evasão na Unipampa- diagnosticando processos, acompanhando trajetórias e itinerários de formação. Universidade Federal do Pampa, 2010.

MENDES, Marcelo Simões. Da inclusão à evasão escolar: O papel da motivação no ensino médio. Campinas: 2013.

PATTO, Maria Helena Souza. A produção do fracasso escolar: histórias de submissão e rebeldia, 1997.

Recebido 30 de maio de 2019 Aprovado 25 de agosto de 2019. 